\title{
APLICACIÓN DE LOS CONVENIOS DE GINEBRA POR LOS TRIBUNALES DE JUSTICIA CHILENOS*
}

\author{
Regina Ingrid Díaz Tolosa ${ }^{* *}$
}

\begin{abstract}
RESUMEN: El presente artículo analiza la vacilante jurisprudencia chilena que se observa en torno a la aplicación de los Convenios de Ginebra en ciertos casos judiciales de Derechos Humanos, a propósito de crímenes de guerra acaecidos durante el Gobierno Militar de Augusto Pinochet Ugarte. La jurisprudencia mayoritaria sostiene su no aplicación por no darse el supuesto de hecho requerido, a saber, la existencia de un conflicto bélico efectivo. Por ello, se examina la discusión acerca de si el estado de sitio decretado en la época puede o no asimilarse a una situación de guerra, particularmente a propósito de la utilización de los tribunales militares de tiempo de guerra durante dicho período. Concluyendo la autora, la necesidad de aplicar estas normas internacionales como debido contrapeso a una legislación especial abusiva y cercenadora de los derechos de las personas; aunque en Chile -como la mayoría de la jurisprudencia lo sostuvo- no hubiera existido un conflicto bélico efectivo, de todos modos debe aplicarse como un fundamental punto de partida de protección mínima el artículo $3^{\circ}$ común a todos los Convenios de Ginebra, donde se plasma el principio de humanidad.
\end{abstract}

Palabras clave: Convenios de Ginebra - Aplicación del Derecho Humanitario - Estado de Sitio - Conflicto bélico - Principio de humanidad

ABSTRACT: This paper reviews the unsteady Chilean Court case law that is observed regarding the application of the Geneva Conventions in certain judicial cases of Human rights, about some crimes of war happened during the Military Government of Augusto Pinochet Ugarte. The majority case law said that these international laws don't have application in the national case because there wasn't the supposition of fact needed: the existence of a warlike effective conflict. This way, it brings over the discussion about if the "State of siege" decreed in that period can or not to be assimilated to a situation of war, particularly about the use of the Military Courts of Time of War during those days. Concluding the authoress, the need to apply these international laws like counterweight to a special improper legislation; though in Chile -as the majority of the case law said it- there wasn't a warlike effective conflict, anyhow must be applied as a fundamental point of minimal protection the $3^{\circ}$ article commonly to all Geneva Conventions, where is contained the principle of humanity.

Key words: Geneva Conventions - Application of the Humanitarian Law - State of siege - warlike conflict - Principle of humanity

\footnotetext{
* Trabajo ganador del Concurso Monografías de Derecho Internacional Humanitario "Premio Gustave Moynier" 2005-2006, destinado a promover el estudio del derecho internacional humanitario y a estimular la reflexión acerca de los desafíos actuales para esa rama del Derecho, organizado por la Delegación del Comité Internacional de la Cruz Roja para Argentina, Brasil, Chile, Paraguay y Uruguay y el Instituto de Derechos Humanos de la Facultad de Ciencias Sociales y Jurídicas de la Universidad Nacional de La Plata.

** Abogada y Doctoranda en Derecho, Pontificia Universidad Católica de Chile.
} 


\section{INTRODUCCIÓN}

En los tribunales de justicia chilenos no se ha aplicado el Derecho Humanitario de manera adecuada; la jurisprudencia no es unánime respecto al hecho de si son o no aplicables los Convenios de Ginebra -fuente material más directa del Derecho Humanitario-, en ciertos casos judiciales de derechos humanos, a propósito de crímenes de guerra acaecidos durante el Gobierno Militar de Augusto Pinochet Ugarte ${ }^{1}$.

Los tribunales de justicia chilenos, en general, niegan la aplicación de los Convenios de Ginebra por no darse el supuesto para ello, a saber: la existencia de un conflicto bélico efectivo.

Sin embargo, existen dos fallos de la Corte de Apelaciones de Santiago -año $1994-^{2}$, dos fallos de la Corte Suprema -uno del año $1998^{3}$ y otro del año $2000^{4}$ - y el más reciente es un fallo de la Corte de Apelaciones de Temuco -año 20045- que acepta la aplicación de estos Convenios, aduciendo que la protección de la persona humana es lo fundamental.

De esta forma, para poder analizar y criticar la aplicación del Derecho Humanitario por los tribunales de justicia chilenos, es imprescindible resumir la discusión que rodea a su aplicabilidad, la cual recae sobre si el estado de sitio, declarado por la Junta de Gobierno presidida por Augusto Pinochet Ugarte, tiene o no como fundamento un conflicto bélico en el cual cabe la aplicación de los Convenios de Ginebra.

La aplicación del Derecho Humanitario en estos casos debió ser plena, pues garantiza el respeto de las personas, y por ende es connatural a todo ser humano. Al analizar la jurisprudencia se podrá ver que la correcta interpretación de los hechos y la aplicación de los Convenios de Ginebra deben buscarse en la voluntad de cumplir con la responsabilidad internacional que ha asumido el Estado al ratificar los mencionados Convenios.

\footnotetext{
${ }^{1}$ A. Pinochet U. gobierna Chile entre 1973 y 1989, primero como Presidente de la Junta de Gobierno, luego como Presidente de la República. Entre el 11 de septiembre de 1973 y el 10 de marzo de 1978, y entre el 6 de noviembre de 1984 y el 17 de junio de 1985 rigió en Chile el estado de sitio, indicándose en su declaración que si bien no existía guerra civil, se aplicarían los tribunales militares de tiempos de guerra.

${ }^{2}$ Contra Romo Mena (1994 a); Contra Romo Mena (1994 b).

3 Poblete Córdova (1998 b).

4 Desafuero Pinochet Ugarte (2000), vid. prevenciones del Ministro Benquis considerandos 20 a $5^{\circ}$, pp. 533-536.

5 Contra Rivera González y otro (2004).
} 


\section{ANÁLISIS DE LA JURISPRUDENCIA CHILENA EN TORNO A LA APLICACIÓN DEL DERECHO HUMANITARIO}

\subsection{No CABE la APliCACiÓn de los CONVEnios De Ginebra}

Se presentan varios casos ante los tribunales de justicia ${ }^{6}$, en los cuales los querellantes sostienen la aplicación de los Convenios de Ginebra, pues el delito en cuestión se habría cometido durante el estado de sitio decretado por la Junta de Gobierno, lo cual, interpretado por el Decreto Ley no 5 de 1973, equivaldría a un estado o tiempo de guerra $^{7}$.

Sin embargo, la Corte Suprema ha sido uniforme en el sentido de negar aplicación a estos acuerdos internacionales, por no darse el supuesto para su aplicación: la existencia de un conflicto bélico efectivo; en el período en que se cometieron los delitos investigados, el estado de sitio declarado no tenía las características de un conflicto armado no internacional, pues:

1. De los artículos $2^{\circ}$ y $3^{\circ}$ que son comunes a los cuatro Convenios de Ginebra, resulta de manifiesto que su aplicación incide y se limita específicamente a casos de guerra declarada, de carácter internacional y sobre situaciones de conflictos armados internos, que surjan dentro del territorio de algunas de las Altas Partes contratantes, tratándose de un efectivo conflicto bélico o de guerra interna, entre partes contendientes armadas $^{8}$.

2. No es posible sostener que al interior del país existieron fuerzas armadas disidentes o grupos organizados que, bajo la dirección de un mando responsable, ejercieran

\footnotetext{
${ }^{6}$ Caso Insunza Bascuñán (1990): Insunza Bascuñán (1990); Caso Videla Moya (1994-1996): Contra Romo Mena (1994 b y 1996); Caso Uribe Tambley y Van Jurick Altamirano (1994-1998): Contra Romo Mena (1994 a y 1995), Contra Romo Mena y otros (1998); Caso Herrera Cofré (1996): Contra Romo Mena y otros (1996); Caso Poblete Córdova (1997-1998): Poblete Córdova (1997), Poblete Córdova (1998 a y b); Caso Weibel Navarrete (1997-2002): Fiscalía de Aviación de Santiago con Dirección de Inteligencia de la Fuerza Aérea (1997, 2001 y 2002); Caso Hermanos Andrónico Antequera (1998): Contra Laureani Maturana y Romo Mena (1998); Caso Pereira Salsberg (1998): Pereira Salsberg y otros (1998); Caso Aranda Romero (1999-2003): Corporación Nacional de Reparación y Reconciliación (1999 y 2003 a); Caso Rioseco Montoya y Cotal Álvarez (2004-2005): Contra Rivera González y otro (2004 y 2005).

${ }^{7}$ La Junta de Gobierno declara en el artículo $1^{\circ}$, del Decreto Ley ${ }^{\circ}$ 5, de 1973: “interpretando el artículo 418 del Código de Justicia Militar que el Estado de Sitio decretado por conmoción interna, en las circunstancias que vive el país, debe entenderse "estado o tiempo de guerra" para los efectos de la penalidad de ese tiempo que establece el Código de Justicia Militar y demás leyes penales y, en general, para todos los demás efectos de dicha legislación”.

8 Cfr. Insunza Bascuñán (1990), considerando 26º, p. 77; Contra Romo Mena y otros (1996), considerando 5․ p. 235; Corporación Nacional de Reparación y Reconciliación (1999), vistos 12 y 15; Ponce Vicencio (1999), considerando $41^{\circ}$; Contreras Cabrera (2002), considerando $17^{\circ}$ letra c) del voto disidente del Auditor General del Ejército, señor Juan Romero Riquelme; Fiscalía de Aviación de Santiago con Dirección de Inteligencia de la Fuerza Aérea (2002), considerando $17^{\circ}$ letra c); Corporación Nacional de Reparación y Reconciliación (2003 a y b), considerando $17^{\circ}$ letra c) del voto disidente del Auditor General del Ejército, señor Juan Romero Riquelme.
} 
sobre una parte del territorio nacional un control suficiente que les permitiera realizar operaciones militares sostenidas y concertadas, por lo que resulta inaplicable la preceptiva de las Convenciones de Ginebra de $1949^{9}$.

3. Mediante Decreto Ley no 3 de 1973 se declaró en estado de sitio por conmoción interna el territorio nacional, lo que no importó el reconocimiento de un estado de tiempo de guerra en el país, lo cual se dispuso solo con el objeto de dar aplicación a la normativa penal militar, tanto sustantiva, procesal y orgánica, según se deja expresamente consignado en el Decreto Ley no 5 del mismo año. En realidad, no concurrían los presupuestos de un conflicto bélico como al que se hace mención en los Convenios de Ginebra. Lo que ocurre es que las autoridades de la época, al concentrar amplias potestades -constituyentes y legislativas-, resolvieron enfrentar la situación de conmoción interna con especial rigurosidad para reprimir y sancionar con una mayor penalidad los detalles contra la seguridad interior del país declarando el estado de sitio por la causal de guerra interna, entre otras razones para activar la jurisdicción militar de tiempos de guerra.

De esta forma, en Chile el estado de guerra solo constituyó una ficción legal que no era reflejo de la realidad experimentada en esa época.

El Decreto Ley no 5 de 1973 no hace declaración alguna de guerra interna y su propósito fue evidentemente de carácter jurisdiccional a fin de permitir la represión de ciertos ilícitos por los tribunales militares, atendida la situación de subversión existente a la fecha, limitándose a señalar que el estado o tiempo de guerra lo es para el solo efecto de la aplicación de la penalidad de ese tiempo ${ }^{10}$.

4. Los actos preventivos, previos o preparatorios de un estado de tiempo de guerra no necesariamente lo constituyen o desembocan en este, por cuanto el acaecimiento de "graves trastornos internos" podrán permitir la actuación de los "tribunales de tiempo de guerra, sin que signifique que el país esté en estado o tiempo de guerra”. La actuación de los tribunales en tiempo de guerra se enmarca dentro de los actos preventivos de dicho tiempo o estado de guerra, al estar dirigido a disuadir actuaciones contrarias a las autoridades constituidas, ya que de hacerlo se les aplicaría la normativa que dicho estado contempla en la legislación penal militar, la que es más rigurosa ${ }^{11}$.

\footnotetext{
${ }^{9}$ Cfr. Contra Romo Mena (1996), considerando 3º p. 458; Poblete Córdova (1998 a), considerando $11^{\circ}$, p. 117; Corporación Nacional de Reparación y Reconciliación (1999), vistos 13 y 14; Ponce Vicencio (1999), considerando $42^{\circ}$ y $44^{\circ}$; Fiscalía de Aviación de Santiago con Dirección de Inteligencia de la Fuerza Aérea (2001), considerando $11^{\circ}$; Contra Rivera González y otro (2005), considerandos $5^{\circ}, 6^{\circ}$ y $7^{\circ}$.

10 Cfr. Contra Romo Mena (1995), considerandos $9^{\circ}$ a $12^{\circ}$, pp. 121 y 122; Contra Romo Mena (1996), considerando 2, p. 457; Contra Romo Mena y otros (1996), p. 236; Contra Laureani Maturana y otro (1998), pp. 138 y 139; Contra Romo Mena y otros (1998), considerando 7o, pp. 127 y 128; Corporación Nacional de Reparación y Reconciliación (1999), vistos 16; Ponce Vicencio (1999), considerando 46; Contra Rivera González y otro (2005), considerandos $7^{\circ}$ y $8^{\circ}$.

${ }^{11}$ V.g. vid. Contra Romo Mena y otros (1998), considerando 8º, p. 128.
} 


\subsection{LOS CONVENIOS DE GINEBRA SON SUSCEPTIBLES DE APLICACIÓN}

Si bien la mayor parte de la jurisprudencia sostiene que los Convenios de Ginebra no tienen aplicación en los hechos delictivos acaecidos en el período de estado de sitio, decretado por la Junta de Gobierno, existen dos fallos, de la Corte de Apelaciones de $1994^{12}$, donde se fundamenta su aplicación. Asimismo, existe un vuelco impresionante de la Corte Suprema, pues aplica los Convenios de Ginebra para aceptar un recurso de casación en $1998^{13}$. Por otra parte, en el fallo de la Corte Suprema que desaforó al entonces senador Pinochet, en el año 2000, en un voto de prevención al voto de mayoría se hace mención a estos acuerdos internacionales. Mientras el fallo más reciente que recoge esta postura emana de la Corte de Apelaciones de Temuco (2004) ${ }^{14}$.

A continuación se exponen las razones que tuvo esta jurisprudencia para afirmar la aplicación de estos Convenios:

1. El artículo $5^{\circ}$ inciso $2^{\circ}$ de la Constitución de 1980, aplicable en esta época, ordena a los órganos del Estado a respetar y promover los derechos esenciales que emanan de la naturaleza humana, garantizados por los tratados internacionales. Mientras que las disposiciones de los Convenios de Ginebra protegen los derechos humanos de los contendientes en caso de guerra externa o conflictos entre fuerzas organizadas de carácter interior de un Estado ${ }^{15}$.

2. En la fecha en que se cometieron los ilícitos existía un conflicto armado, invocándose, para probarlo, el Decreto Ley no 5 de 1973, que señala que debe entenderse estado o tiempo de guerra al estado de sitio decretado por conmoción interna para los efectos de la aplicación de la penalidad, de tiempo de guerra que establece el Código de Justicia Militar.

De acuerdo al artículo 1º, del referido Decreto: "Declárese, interpretando el artículo 418 del Código de Justicia Militar que el Estado de Sitio decretado por conmoción interna, en las circunstancias que vive el país, debe entenderse "estado o tiempo de guerra" para los efectos de la penalidad de ese tiempo que establece el Código de Justicia Militar y demás leyes penales y, en general, para todos los demás efectos de dicha legislación”. Entre esa legislación aplicable en un estado o tiempo de guerra, e incluso en conflictos armados sin carácter internacional, se encuentran los Convenios de Ginebra de $1949^{16}$.

\footnotetext{
12 Vid. n. 2.

13 Vid. n. 3.

14 Vid. n. 4.

15 Vid. Contra Romo Mena (1994 b), considerandos 8o y 9º pp. 132 y 133; Poblete Córdova (1998 b), considerando $10^{\circ}$, p. 122; Corporación Nacional de Reparación y Reconciliación (2003 a), Informe fiscal Corte Suprema.

${ }^{16}$ Vid. Contra Romo Mena (1994 b), considerando 5, p. 128; Contra Romo Mena y otros (1998), considerando $8^{\circ}$ del voto disidente, p. 131; Poblete Córdova (1998 b), considerando 9², p. 121; Desafuero Pinochet Ugarte (2000), considerandos 20 y 3º, pp. 533 y 534; Corporación Nacional de Reparación y Reconciliación (2003 a), Informe fiscal Corte Suprema.; Contra Rivera González y otro (2004), considerando 4 ${ }^{\circ}$ Contra Rivera González y otro (2005), considerandos $1^{\circ}$ y $2^{\circ}$ del voto disidente de los ministros señores Enrique Cury y Jaime Rodríguez Espoz, quienes estuvieron por rechazar el recurso de casación interpuesto por los condenados en segunda instancia.
} 
3. El artículo 418 del Código de Justicia Militar, vigente a la fecha, establecía que: "Para los efectos de este Código, se entiende que hay estado de guerra, o que es tiempo de guerra, no solo cuando ha sido declarada oficialmente la guerra o el estado de sitio, en conformidad a las leyes respectivas, sino también cuando de hecho existiera la guerra o se hubiere decretado la movilización para la misma, aunque no se haya hecho su declaración oficial" 17 .

4. Había conmoción interior provocada por fuerzas rebeldes o sediciosas organizadas que operaban en forma abierta o clandestina y durante todo el período rigieron los tribunales, los procedimientos y las penalidades de tiempo de guerra, como asimismo, había una acción militar al mando de un jefe especialmente nombrado al efecto, con atribuciones para dictar bandos ${ }^{18}$.

5. Los artículos 146, 147 y 148 de los Convenios son de aplicación amplia aun fuera del estado de guerra: es el repudio de toda acción delictual que lleve a la comisión de "homicidio adrede, tortura o tratos inhumanos", y es obvio que si estos delitos no pueden cometerse durante una guerra, mucho menos pueden ser cometidos durante el tiempo de paz. El convenio internacional estableció una garantía de esos derechos fundamentales del ser humano que no pueden ser quebrantados en ninguna circunstancia ${ }^{19}$.

6. El Estado de Chile se impuso en los citados Convenios la obligación de garantizar la seguridad de las personas que pudieren tener participación en conflictos armados dentro de su territorio, especialmente si fueren detenidas, quedando vedado el disponer medidas que tendieren a amparar los agravios cometidos contra personas determinadas o lograr la impunidad de sus autores, teniendo especialmente presente que los acuerdos internacionales deben cumplirse de buena $\mathrm{fe}^{20}$.

\section{EXISTENCIA DE UN CONFLICTO ARMADO, PREMISA PARA LA APLI- CACIÓN DEL DERECHO HUMANITARIO}

El 11 de septiembre de 1973 las Fuerzas Armadas y de Orden derrocan el Gobierno de Salvador Allende Gossens, asumiendo el mando de la nación la Junta de Gobierno presidida por el Comandante en Jefe del Ejército, General Augusto Pinochet Ugarte. La Junta declaró al país en estado de sitio -Decreto Ley no $3-$ y en estado de emergencia -Decreto Ley no 4-, ambos a contar del 11 de septiembre de 1973. Además, en virtud

\footnotetext{
17 Vid. Contra Romo Mena (1994 b), considerando $5^{\circ}$ letra b), p. 128; Contra Rivera González y otro (2005), considerandos $1^{\circ}$ y $2^{\circ}$ del voto disidente de los ministros señores Enrique Cury y Jaime Rodríguez Espoz, quienes estuvieron por rechazar el recurso de casación interpuesto por los condenados en segunda instancia.

${ }^{18}$ Vid. Contra Romo Mena (1994 b), considerando $5^{\circ}$ letra c), p. 128.

19 Vid. Contra Romo Mena (1994 b), considerandos 80 y 9o, pp. 132 y 133; Corporación Nacional de Reparación y Reconciliación (2003 a), Informe fiscal Corte Suprema; Contra Rivera González y otro (2004), considerando $5^{\circ}$.

20 Vid. Contra Romo Mena (1994 b), considerandos 8o y 9o, pp 132 y 133; Poblete Córdova (1998 b), considerando $10^{\circ}$, p. 122; Contra Rivera González y otro (2004), considerando $4^{\circ}$.
} 
del Decreto Ley no 5 de 1973, se interpretó que el estado de sitio implantado debería entenderse como estado o tiempo de guerra ${ }^{21}$.

En consideración de la Junta de Gobierno, "Chile se encontraba en un proceso de destrucción sistemática e integral, por efecto de la intromisión de una ideología dogmática y excluyente, inspirada en los principios foráneos del marxismo-leninismo"22. El 13 de septiembre de 1973 el Comité Central del Partido Comunista de la URSS emitió una declaración en la que junto con repudiar el Golpe Militar y declarar formalmente rotas las relaciones diplomáticas y consulares con Chile, anunciaba que de acuerdo a la Doctrina sobre la Irreversibilidad de los Procesos Revolucionarios, el Gobierno Soviético se reservaba todos los medios a su alcance para revertir la situación ${ }^{23}$.

Entonces, comenzó una lucha subversiva, la que adoptó formas abiertas, es decir, enfrentamientos directos con las Fuerzas Armadas y de Orden y el terrorismo, es decir, el ataque solapado a personas y bienes. Se inició una verdadera guerra civil larvada, de carácter extremadamente violento, con bajas por ambos bandos y que en la práctica no se interrumpió más, continuando incluso bajo el primer Gobierno de la Concertación, con los asesinatos de militares y el senador Jaime Guzmán ${ }^{24}$.

Este período se caracterizó por el factor ideológico, con la abierta intervención de factores foráneos. El país se polarizó en varios extremos. Por una parte, quienes pretendían derribar al Gobierno valiéndose de lo que entonces se denominó Resistencia Civil, la que se expresaba en paros, protestas y otras expresiones más o menos pacíficas, invariablemente desvirtuadas por el otro sector de la oposición, constituido por las fuerzas de extrema izquierda, sector que optó en todo momento por la lucha armada y el terrorismo, no deteniéndose ante ningún exceso para lograr su objetivo, consistente no solo en derribar el Gobierno Militar, sino en restablecer el proyecto marxista-leninista de apoderarse del poder total. El asesinato, el atentado terrorista, el robo, el sabotaje, fueron sus medios de acción, nunca disimulados ni desmentidos por lo demás ${ }^{25}$.

A raíz de estos sucesos históricos, en varios juicios se han invocado los Convenios de Ginebra, sin embargo, la mayoría de la jurisprudencia niega su aplicación, argumentando que Chile en este período no se encontraba en una situación de conflicto armado efectivo. A pesar de ello, existe parte de la doctrina y de la jurisprudencia que sostienen la existencia de una verdadera guerra civil.

\subsection{El estado de Sitio deClarado pOR la JUNTA DE GOBIERNO SE FUNDA EN LOS DISTURBIOS O TENSIONES INTERIORES EXISTENTES \\ De acuerdo a esta tesis, el estado de sitio solo tiene su fundamento en una situación de disturbio o tensión interior existente, bajo la cual no cabe la aplicación de}

\footnotetext{
${ }^{21}$ Vid. n. 7.

22 Artículo 2o del Decreto Ley no 1 de 1973.

23 El Mercurio, 15 septiembre 1973.

${ }^{24}$ CALDERÓN (1996) p. 225.

25 Ídem, p. 248.
} 
los Convenios de Ginebra, pues el Protocolo II excluye expresamente de su ámbito de aplicación estas situaciones.

La Constitución de 1925 contemplaba dos tipos de estados de excepción, el estado de asamblea y el estado de sitio; aquel era procedente en caso de guerra externa, y este, en situación de conmoción interna.

El Informe sobre la situación de los Derechos Humanos en Chile, adoptado por la Comisión Interamericana de Derechos Humanos, en 1985, señala que interesa a los fines de ese Informe la "declaración del estado de sitio por conmoción interna"26.

En situaciones de perturbación del orden público, el Derecho Humanitario no tiene aplicación. Ello no obsta a que el Comité Internacional de la Cruz Roja pueda visitar detenidos. Sin embargo, al hacerlo, obra conforme a sus propios Estatutos, no a las Convenciones de Ginebra ${ }^{27}$. Así ocurrió en el caso chileno durante el Gobierno de Pinochet ${ }^{28}$.

Valga la observación de que los gobiernos autoritarios suelen invocar la presencia de un estado de guerra interna en circunstancias en que a lo sumo existe una alteración de la tranquilidad pública (a menudo causada por los "ímpetus" de las propias autoridades). Curiosamente, no obstante, en el contexto de esta falacia las autoridades no aplican el Derecho Humanitario, al tiempo que pretenden justificar sus violaciones a los derechos humanos ${ }^{29}$.

En opinión de la Comisión Chilena de Derechos Humanos, aplicando estrictamente el Derecho Internacional, no es posible sostener que en Chile haya existido guerra, por lo que los métodos militares, tales como consejos de guerra, campos de prisioneros, ocupación militar de ciudades y sus secuelas, etc., solo constituyeron abusos y violaciones a los derechos de todos los habitantes del país, y por tanto infracción grave al Derecho Internacional de los Derechos Humanos ${ }^{30}$.

\subsection{El estado de Sitio deClarado por la JUNTA DE Gobierno EQUiVAle A UN ESTADO O TIEMPO DE GUERRA}

Bajo esta teoría el estado de sitio declarado por la Junta de Gobierno equivale a un estado o tiempo de guerra, por ende sería una situación que equivaldría a un conflicto bélico interno cubierto por el artículo $3^{\circ}$ de la Convención de Ginebra, y por tanto tal normativa sería aplicable.

\footnotetext{
${ }^{26}$ Vid. Comisión Interamericana de Derechos Humanos (1985) pp. 24 - 26.

27 En el punto 5, del artículo VI de los Estatutos de la Cruz Roja Internacional, adoptados por la Conferencia Internacional de la Cruz Roja, en La Haya, en 1928, y revisados en Toronto en 1952, se señala que el Comité Internacional de la Cruz Roja es una "institución neutral, cuya actividad humanitaria se ejerce especialmente en caso de guerra, de guerra civil o de perturbaciones interiores, se esfuerza, en todo tiempo, en asegurar protección y asistencia a las víctimas militares y civiles de dichos conflictos y de sus consecuencias directas (...)”. (Comité Internacional de la Cruz Roja, 1975, p. 282).

28 González (1993) p. 34.

29 Ídem, pp. 34 y 35.

${ }^{30}$ Comisión Chilena de Derechos Humanos (1994) p. 22.
} 


\subsubsection{Decreto Ley no 5 de 1973}

Lo que da mayor sustento a esta teoría es la interpretación que hace de la declaración del estado de sitio el decreto Ley no 5 de 1973, pues en forma textual declara que debe entenderse como estado o tiempo de guerra: "Declárese interpretado el artículo 418 del Código de Justicia Militar, que el Estado de Sitio decretado por conmoción interna, en las circunstancias que vive el país, debe entenderse "estado o tiempo de guerra" para los efectos de la aplicación de la penalidad de ese tiempo que establece el Código de Justicia Militar y demás leyes penales y, en general, para todos los demás efectos de dicha legislación".

Este instrumento modifica, como puede advertirse, la tipología existente sobre estados de excepción. En efecto, el Decreto Ley no 5, de 1973, concede categoría de tal a la conmoción interior y afecta el orden normativo que regula los derechos reconocidos y sus limitaciones bajo los estados de excepción ${ }^{31}$.

Incluso, el Código de Justicia Militar, en su artículo 418, hace equiparable el estado de sitio al estado de guerra: "Para los efectos de este Código, se entiende que hay estado de guerra, o que es tiempo de guerra, no solo cuando ha sido declarada oficialmente la guerra o el estado de sitio, en conformidad a las leyes respectivas, sino también cuando de hecho existiere la guerra o se hubiere decretado la movilización para la misma, aunque no se haya hecho su declaración oficial". De esta norma legal se desprende que el estado de guerra existió, claramente en nuestro país, desde las primeras horas del 11 de septiembre de $1973^{32}$.

\subsection{Dichos de la Junta de Gobierno y SUS SEGUidoreS}

Al cumplirse un mes desde la fecha de constitución de la Junta de Gobierno, el presidente de la misma pronuncia un discurso en el que habla de que subsiste el estado de guerra: "La situación se controla, pero persiste la amenaza externa e interna de chilenos que se sienten rabiosamente defraudados en sus propósitos totalitarios y, desde otros países, incitan a extranjeros, a luchar contra sus propios hermanos. Por ello, subsisten el estado de guerra interno y el estado de sitio (...)"33.

Según el gremialismo, en un principio se dio una situación de enfrentamiento, en la que tuvieron lugar "excesos y acciones desmedidas", propias de circunstancias bélicas. De ahí que puedan considerarse justificables. Sin embargo, instalado el nuevo gobierno, "establecida y asegurada la paz social", los excesos que continuaron cometiéndose no pueden ser considerados en la forma anterior: "Hubo excesos que no son justificables ni legítimos bajo ningún punto de vista" 34 .

Durante este período se cometen una serie de graves violaciones a los derechos humanos, que constituyen crímenes de acuerdo a la legislación penal tradicional chilena (detenciones con desaparición, ejecuciones administrativas, torturas, etc.). Los organis-

\footnotetext{
31 Comisión Interamericana de Derechos Humanos (1985), p. 29.

32 Aycinema y Ramírez (1974), considerando 5º p. 107.

33 El Mercurio, 12 octubre 1973.

${ }^{34}$ Politzer (1985), p. 214.
} 
mos de derechos humanos consideran que durante este período se concentra más del $60 \%$ de los más graves atentados contra dichos derechos. Según el planteamiento gubernativo, tales excesos se debieron a la resistencia armada de partidarios del gobierno depuesto, de tipo subterráneo y encubierta, con la cual se preparaba la subversión política y terrorista ${ }^{35}$.

Para combatir la subversión que se prolongó durante los años que siguieron al golpe de Estado, las fuerzas de seguridad recurrieron a métodos especiales, por cuanto "haber pretendido librar este combate con los métodos propios de un período normal, hubiese significado sucumbir ante la subversión, y permitir que Chile fuera manchado con la sangre de la lucha fratricida o del caos terrorista". Esta subversión era organizada "con la magnitud propia de una guerra civil", y era apoyada desde el extranjero ${ }^{36}$.

Por su parte, el Ejército de Chile sustentó, en la presentación hecha a la Comisión Nacional de Verdad y Reconciliación, que Chile vivía al 11 de septiembre de 1973 un estado de guerra civil, en donde tuvo que asumir el poder e hizo frente junto a las demás ramas de las Fuerzas Armadas y de Orden a los grupos paramilitares de izquierda. Para la institución armada los signos externos de un conflicto civil son variados, pero todos ellos eran reconocibles en el país: víctimas fatales y heridos en todos los sectores; familias divididas, una economía devastada, los poderes públicos superados por los acontecimientos y en definitiva el restablecimiento de la paz y del imperio de derecho mediante el uso de la fuerza por parte de sus legítimos detentadores: Las Fuerzas Armadas y Carabineros de Chile ${ }^{37}$.

\subsection{USO DE LOS TRIBUNALES MILITARES DE TIEMPO DE GUERRA DURANTE EL PERÍODO DE VIGENCIA DEL ESTADO DE SITIO \\ En virtud de los decretos que declaran el estado de sitio, y del Decreto Ley no 5} de 1973 que hace aplicable la legislación militar, la jurisprudencia avalaba la aplicación de la jurisdicción militar de tiempo de guerra: “(...) declarado el país en estado de guerra por los Decretos Leyes $\mathrm{n}^{\text {os }} 3$ y 5 , de 11 y 25 de septiembre último, situación excepcional que actualmente se mantiene rigen para todo el país las leyes de guerra entre los cuales figuran las normas del Código de Justicia Militar que establecen los Tribunales Militares en tiempo de guerra"38.

La justicia militar constituye una jurisdicción especial. La organización y funcionamiento de los tribunales militares en tiempo de guerra eran regulados por los artículos 71 a 91 y 180 a 196 del Código de Justicia Militar, los cuales dentro del período de estado de sitio -en análisis- no presentaron modificaciones, según se constata entre la $7^{\text {a }}$ y la $13^{a}$ edición oficial del mencionado Código ${ }^{39}$.

\footnotetext{
35 VIERA y RODRÍGUEZ (1988) p. 35.

36 Ibídem.

37 Cfr. EjérCito de Chile (1990) pp. 11-14.

38 J.F.S.R. (1973) pp. 100 y 101.

39 Vid. Código de Justicia Militar, 7a edición oficial de 1973; 9a edición oficial de 1976; 12a edición oficial de 1984; y 13a edición oficial de 1985.
} 
Estas disposiciones configuran un ordenamiento jerárquico autónomo e independiente de toda otra autoridad de la jurisdicción ordinaria o especial, ordenamiento que culmina en el General en Jefe a quien se otorga la plenitud de esta jurisdicción. Así, de acuerdo a esta legislación, en tiempo de guerra la jurisdicción militar era ejercida por "los Generales en Jefe o Comandantes superiores de plazas o fortalezas sitiadas o bloqueadas, o de divisiones o cuerpos que operen independientemente; por los Fiscales y por los Consejos de Guerra y Auditores" ${ }^{40,41}$. Y, "al General en Jefe de un Ejército le corresponde el ejercicio pleno de la jurisdicción militar en las fuerzas de su mando y en el territorio que con ellas ocupe, comprendida la jurisdicción disciplinaria” ${ }^{2}$.

Los tribunales militares en tiempo de guerra entran a actuar cuando concurren los siguientes requisitos: a) Que el territorio nacional sea declarado en estado de asamblea o de sitio; b) que se nombre un General en Jefe; c) que exista un enemigo extranjero o fuerzas rebeldes organizadas para operar en su contra ${ }^{43}$, 44 . Cabe destacar que al comenzar la competencia de los tribunales militares de tiempo de guerra, cesa la de los tribunales militares del tiempo de paz ${ }^{45}$.

Los tribunales militares de tiempo de guerra fueron estructurados sobre la base de Consejos de Guerra ${ }^{46}$ que requieren de un jefe militar que los convoca y que puede aprobar, revocar o modificar la sentencia ${ }^{47}$, y de un fiscal en cargado de la investigación

${ }^{40} \mathrm{Si}$ bien los auditores también se incluyen en el artículo 71 del Código de Justicia Militar como tribunal de tiempo de guerra, "ellos no ejercen jurisdicción militar de tiempo de guerra sino como integrantes de los Consejos de Guerra; las demás funciones que tienen son de auxiliar asesor del Comandante en Jefe”. (Astrosa, 1985, p. 126).

${ }^{41}$ Artículo 71 del Código de Justicia Militar, vigente entre 1973 y 1985.

42 Ídem, artículo 74.

43 Aycinema y Ramirez (1974), considerando $3^{\circ}$, p. 106.

44 "Con respecto a la existencia de fuerzas rebeldes organizadas, tercer requisito señalado, es público y notorio que las Fuerzas Armadas a partir del amanecer del día 11 de septiembre de 1973 fueron resistidas y atacadas por grupos armados organizados". Ídem, considerando 8º p. 108.

45 Ello se concluye del análisis de los artículos 72 y 73 del Código de Justicia Militar, y del artículo único del Decreto Ley no 13 de 1973. (Artículo 72: "La jurisdicción militar de tiempo de guerra comprende: el territorio nacional declarado en estado de asamblea o de sitio, sea por ataque exterior o conmoción interior, de acuerdo con el número 17 del artículo 72 de la Constitución Política; y el territorio extranjero ocupado por las armas chilenas"; Artículo 73: "Desde el momento en que se nombre General en Jefe de un Ejército que deba operar contra el enemigo extranjero o contra fuerzas rebeldes organizadas, cesará la competencia de los Tribunales Militares del tiempo de paz y comenzará la de los Tribunales Militares del tiempo de guerra, en todo el territorio declarado en estado de asamblea o de sitio. / Igual cosa sucederá en la plaza o fortaleza sitiada o bloqueada, desde el momento que su Jefe proclame que asume en ella toda la autoridad"; Artículo único: "Declárese que el sentido y alcance del artículo 73 del Código de Justicia Militar es el de entregar a los Tribunales Militares del tiempo de guerra el conocimiento de los procesos de la jurisdicción militar iniciados en el territorio declarado en Estado de Asamblea o de Sitio con posterioridad al nombramiento del General en Jefe; quedando sometidas a los Tribunales Militares del tiempo de paz y con arreglo al procedimiento militar de este tiempo el conocimiento y juzgamiento de las causas que llevaban adelante, hasta su total terminación").

46 Artículo 81 del Código de Justicia Militar: "De todos los delitos que corresponda juzgar a la jurisdicción militar en tiempo de guerra, conocerán en única instancia los Consejos de Guerra”.

${ }^{47}$ Artículo 88 del Código de Justicia Militar: "Pronunciada la sentencia, el Consejo la remitirá al General en Jefe o Comandante que hubiere ordenado su formación, para su cumplimiento, previa su aprobación”. 
sumarial. Se debe hacer notar que el procedimiento usado por estos tribunales, reglamentado en el Libro II del Código de Justicia Militar -artículos 180 a 196-, da a los imputados infinitamente menores garantías procesales que cuando son encausados por tribunales y procedimientos de tiempo de $\mathrm{paz}^{48}$.

En general, se pueden distinguir las siguientes características de los tribunales de tiempo de guerra: a) Son tribunales colegiados ${ }^{49}$ (Consejos de Guerra), de única instancia (sin perjuicio de la aprobación, enmienda o revocación del Comandante en Jefe ${ }^{50}$ ), integrados, a excepción del auditor, por elementos militares no letrados; b) Son tribunales que no integran el Poder Judicial, o sea, que no se encuentran sometidos a la supervigilancia correccional y disciplinaria de la Corte Suprema, pues no ejercen propiamente funciones judiciales, sino que de mando por delegación del Jefe de Estado; c) Son tribunales que tienen una jurisdicción más amplia que los del tiempo de paz, en atención a que deben conocer, además, de los delitos marciales, o sea, aquellos que han sido creados por los bandos militares. Por otra parte la calidad de militar la adquieren mayor número de personas ${ }^{51}$.

De esta forma, además de la composición y los extensos poderes otorgados al jefe militar que convoca al Consejo de Guerra, hay aspectos de procedimiento que disminuyen pronunciadamente el derecho de un acusado a un juzgamiento imparcial y justo ${ }^{52}$ :

1. La preparación del sumario fiscal es secreta y no puede durar más de 48 horas. Una vez completado, el sumario es presentado al jefe militar, quien lo revisa y convocará un Consejo de Guerra si decide que el caso tiene suficientes pruebas y méritos. El abogado del acusado solo tiene acceso al sumario del fiscal el día que el Comandante en Jefe convoca el Consejo de Guerra y solo tiene tiempo para prepararse el día en que el Consejo de Guerra se reúne. El Código no señala el tiempo mínimo que debe pasar entre el momento en que el defensor tiene acceso al sumario del fiscal y el momento mismo en que el Consejo se reúne. En efecto, el tiempo otorgado al abogado para preparar la defensa de su cliente está sujeto a la discreción del Comandante en Jefe que convoca al Consejo ${ }^{53}$.

\footnotetext{
48 Astrosa (1985) p. 125.

49 "La Corte Suprema no tiene ningún poder de revisión sobre las decisiones del Consejo de Guerra, ello es particularmente ominoso pues el Consejo de Guerra está integrado por siete personas, todas las cuales son miembros activos de las Fuerzas Armadas, menos el Auditor, quien debe tener instrucción legal (Vid. Artículos 82 y 83 del Código de Justicia Militar)” (LópeZ, 1995, p. 62).

50 "Cualquier decisión del Consejo de Guerra puede ser modificada e incluso revocada por el Jefe Militar que lo convocó. Esto puede resultar en la posibilidad que una sentencia absolutoria del Consejo de Guerra sea anulada por el Jefe Militar sin ningún tipo de recurso disponible para el acusado”. Ibídem.

${ }^{51}$ Astrosa (1985) pp. 126 y 127.

52 LÓPEZ (1995) pp. 62-64.

53 Artículo 183 del Código de Justicia Militar: "El decreto que ordena la convocación del Consejo de Guerra señalará el lugar, día y hora en que debe funcionar; y ordenará también ponerlo en conocimiento del o los inculpados con el mandamiento de que en el acto deben señalar su defensor. / Al inculpado que no designare en el acto su defensor, se le designará uno de oficio por el Fiscal”.
} 
2. Durante la sesión misma del Consejo de Guerra, el fiscal es libre para presentar todas las pruebas y testimonios que él estime conveniente para el caso. El defensor, en cambio, está limitado a leer un resumen escrito ya preparado. El defensor no tiene la oportunidad de refutar o debatir ninguno de los cargos o alegatos hechos por parte del fiscal ${ }^{54}$.

3. Si el defensor comete una falta de respeto de tal gravedad que dificulta el funcionamiento del Consejo, puede ser retirado, continuando la causa sin su intervención ${ }^{55}$.

4. Aplicación de procedimientos severos, tales como: incomunicaciones prolongadas $^{56}$ y amenazas ${ }^{57}$.

\subsection{DECRETO LEY No 640 DE 1974}

Este Decreto en su artículo $6^{\circ}$ distingue cuatro grados de estado de sitio: a) por guerra interna o externa; b) en grado de defensa interna en caso de conmoción interior provocada por fuerzas rebeldes o sediciosas que se encuentren organizadas o por organizarse, ya sea en forma abierta o en la clandestinidad; c) en grado de seguridad interior, que procederá cuando la conmoción sea provocada por fuerzas rebeldes o sediciosas que se encuentren organizadas, y d) en grado de simple conmoción interior, que procederá en los demás casos previstos en la legislación vigente.

El artículo $7^{\circ}$ del mismo, contempla el funcionamiento de los Tribunales de Tiempo de Guerra en los dos primeros grados de estado de sitio, lo que está conforme, en general, con lo que se expresa en los artículos 72, 418 y 419 del Código de Justicia Militar:

Artículo 72: "La jurisdicción militar de tiempo de guerra comprende: el territorio nacional declarado en estado de asamblea o de sitio, sea por ataque exterior o conmoción interior, de acuerdo con el número 17 del artículo 72 de la Constitución Política; y el territorio extranjero ocupado por las armas chilenas";

54 Artículo 191 del Código de Justicia Militar, incisos 20 y 3: "El fiscal hará una relación del sumario, terminando con la lectura del dictamen o de los cargos formulados por el Comandante en Jefe a que se refieren los artículos 180 y 181. / En seguida, el reo o defensor leerán la defensa, la que debe contener las conclusiones que creyeren del caso, sosteniendo la inculpabilidad del reo o las causales que atenúen su responsabilidad".

55 Artículo 196 del Código de Justicia Militar, inciso 4º "Las faltas de respeto del defensor se castigarán después que haya cumplido su misión, salvo que fueren de tal gravedad que dificultaren el funcionamiento del Consejo, en cuyo caso se le hará retirarse, si así lo resuelve el Consejo, continuando la causa sin su intervención".

56 "Se hizo una costumbre para los fiscales militares el incomunicar por largos períodos a los detenidos apenas les eran puestos a su disposición por parte del organismo aprehensor. Estos períodos oscilaban entre los 10 y 70 días. Cabe tener presente que los sicólogos han elaborado estudios e informes sobre el particular concluyendo que la incomunicación prolongada constituye una forma de tortura: al término de cuatro días de aislamiento aparece ansiedad, desasosiego, irritabilidad, fantasías atemorizantes, vivencias de despersonalización, entorpecimiento del juicio reflexivo y dificultad para mantener un juicio independiente; al $7^{\circ}$ día de aislamiento se agrega la angustia, sensaciones corporales extrañas, dificultad de atención y concentración” (López, 1995, p. 63).

57 "El procedimiento penal permitía que el detenido fuese interrogado por el juez o fiscal sin la presencia de un abogado, lo que da pie a toda clase de especulaciones afectándose el derecho del detenido y el prestigio del tribunal”. Ídem, p. 64. 
Artículo 418: "Para los efectos de este Código, se entiende que hay estado de guerra, o que es tiempo de guerra, no solo cuando ha sido declarada oficialmente la guerra o el estado de sitio, en conformidad a las leyes respectivas, sino también cuando de hecho existiere la guerra o se hubiere decretado la movilización para la misma, aunque no se haya hecho su declaración oficial";

Artículo 419: "Se considera que una fuerza está "frente al enemigo" no solo cuando notoriamente lo tenga a su frente, sino desde el momento que haya emprendido los servicios de seguridad en contra de él.

Y se entiende por "enemigo", para estos efectos, no solamente el extranjero, sino cualquiera clase de fuerzas rebeldes o sediciosas organizadas militarmente".

\subsection{DeCRETO LeY No 2.191 DE 1978}

Esta norma de amnistía deja sin sanción los hechos ilícitos ocurridos entre el 11 de septiembre de 1973 y el 11 de marzo de 1978, pero no definió el significado de la palabra amnistía. Sin embargo, hay consenso que procede del griego amnesis, que significa olvido ${ }^{58}$; y de que por ser el Estado el único que tiene la potestad de castigar delitos puede renunciar parcialmente a dicha facultad para dejar sin sanción alguno de estos en períodos de grave perturbación política o revolucionaria con el propósito de restablecer la paz social y la estabilidad institucional perturbada o amenazada ${ }^{59}$.

De esta forma, este Decreto fue dictado para dejar sin sanción hechos ilícitos ejecutados en un período de grave perturbación política o revolucionaria por la aplicación de la justicia militar en tiempo de guerra a los disidentes al Gobierno Militar, situación expresamente comprendida en el artículo $3^{\circ}$ común a los cuatro Convenios de Ginebra.

Sin embargo, la amnistía como causal de extinción de responsabilidad penal de crímenes de guerra o de lesa humanidad está expresamente prohibida por los Convenios Internacionales y el Protocolo Adicional II, complementario del artículo $3^{\circ}$ de los Convenios de Ginebra, al hablar de amnistía se refiere "al recurso de las armas", como también a los delitos que tienen el carácter de políticos o conexos con esta circunstancia, y no se refiere en ningún caso a los crímenes cometidos fuera de las acciones bélicas ya que, de no ser así, sería contrario a la Convención de Ginebra.

\footnotetext{
58 "La amnistía es una institución propia del Derecho Occidental, cuyos orígenes se remontan a la antigua Grecia y a la República romana. Ya el legislador Solón se refería a ella, calificándolo como un mal necesario e inevitable, para sanar las llagas del cuerpo social. Es decir, ya desde entonces la amnistía era una institución más política que jurídica y también desde entonces se la entendía en su real acepción: el olvido, en otras palabras, la única forma de superar situaciones que en su momento quebrantaran la paz social era olvidarlas y ello implicaba la suposición que los hechos delictuosos que se amnistiaban no habían ocurrido nunca y por lo tanto no solo no eran reprochables sino que además no habían existido" (Calderón, 1996, p. 249).

59 Cfr. Insunza Bascuñán (1990) p. 65.
} 


\subsection{Dichos Del EjérCiTo De Chile}

El Ejército de Chile plantea, en la presentación que hace a la Comisión Nacional de Verdad y Reconciliación ${ }^{60}$, que Chile vivía al 11 de septiembre de 1973 un estado de guerra civil, en donde tuvo que asumir el poder e hizo frente junto a las demás ramas de las Fuerzas Armadas y de Orden a los grupos paramilitares de izquierda ${ }^{61}$.

Se plantea en forma progresiva y generalizada una situación de arbitrariedad, anarquía y violencia armada: 1. La paz social es turbada por desavenencias fundamentales entre bandos de la nación, quebrándose la tranquilidad pública, introduciéndose alteraciones graves a la convivencia social; 2. La grave situación es percibida por el grueso de la opinión pública; 3. Los mecanismos instituciones progresivamente dejan de funcionar; 4. Existe una lucha armada entre bandos de una misma nación, los cuales se agreden metódicamente entre sí, por motivos ideológicos-políticos ${ }^{62}$.

\section{CONCLUSIONES}

A nuestro juicio, no se puede afirmar con certeza absoluta la existencia de una guerra civil, luego del golpe militar de 1973, y no se puede cambiar la naturaleza jurídica del estado de sitio. Si bien se ha probado la existencia de, al menos, disturbios interiores, no se puede afirmar con certeza absoluta si existió o no una guerra civil no declarada, pues la historia está creada sobre la base de interpretaciones; así algunos sostienen la existencia de una verdadera guerra; otros, en cambio, solo indican la existencia de una conmoción interna.

Ahora bien, aunque no se pueda asegurar fehacientemente la existencia de una real guerra civil, se cree que ello no es obstáculo para la aplicación de los Convenios de Ginebra, puesto que si el Decreto Ley no 5 de 1973 y el Decreto Ley no 640 de 1974 hicieron aplicable la legislación de tiempo de guerra, dentro de esta se encuentran precisamente estos acuerdos internacionales.

Recordemos que en virtud de los decretos leyes que declaran al país en estado de sitio, y el Decreto Ley no 5 de 1973, que hace aplicable la legislación militar durante la vigencia de esta situación de emergencia, se aplicó la jurisdicción militar, siendo competentes los tribunales militares en tiempo de guerra. Siendo la jurisdicción penal militar de tiempo de guerra cercenadora de los derechos procesales trascendentales del imputado, deben aplicarse los Convenios de Ginebra como debido contrapeso a esta jurisdicción abusiva, que por ello mismo solo se justifica en caso de guerra ${ }^{63}$, siendo limitada en

${ }^{60}$ Esta Comisión fue creada especialmente para investigar los casos de violaciones a los derechos humanos durante el período del Gobierno Militar, la cual trabajó durante el Gobierno de Aylwin Azócar.

${ }^{61}$ Cfr. EJÉRCiTO DE CHILE (1990) pp. 11-14.

62 Ídem, pp. 15 y 16.

63 "Un General en Jefe de un Ejército o de una Armada, es la máxima autoridad militar de tiempo de guerra, quien tiene atribuciones excepcionales de todo orden, que solo una situación de extrema gravedad para el Estado mismo puede justificar. Como en el General en Jefe del Ejército se ha depositado la mayor responsabilidad por el éxito de las operaciones de la guerra, el legislador le ha conferido atribuciones tales que en tiempo de paz no tienen ni las más altas autoridades políticas o administrativas. Sus atribuciones son disciplinarias, jurisdiccionales, legislativas y administrativas” (ASTROSA, 1985, p. 131). 
cuanto al espacio y al tiempo. Si esta jurisdicción es solo aceptable bajo estos supuestos, la ficción legal emanada del Decreto Ley no 5 , de 1973, constituye un evidente atropello a los derechos fundamentales de la persona, y por ello debía acogerse la aplicación de los citados Convenios en los casos en los cuales la jurisprudencia lo negó, aduciendo una falta de conflicto bélico efectivo ${ }^{64}$.

De esta forma, al no dar aplicación a los Convenios de Ginebra, han existido graves infracciones al Derecho Humanitario o graves crímenes contra los derechos humanos, tales como desapariciones forzosas, ejecuciones sumarias ${ }^{65}$, uso de los Consejos de Guerra y de las fiscalías militares ad hoc, aplicación de la tortura, incomunicaciones prolongadas y destierros, entre otros.

Así pues, no se respeta el derecho de ser juzgados por un tribunal competente, independiente e imparcial, pues la composición del único tribunal de tiempo de guerra (Consejo de Guerra) aparece violando este derecho, ya que seis de los siete jueces no tienen instrucción legal, y todos son oficiales militares en servicio activo y, en consecuencia, jerárquicamente subordinados a sus superiores. Más contrario aún a este derecho, aparece el poder de la autoridad convocante de un Consejo de Guerra; un militar sin instrucción legal puede revocar o modificar las decisiones del Consejo, si así lo desea.

Lo propio ocurre con el derecho a disponer del tiempo y de los medios adecuados para la preparación de la defensa, pues en el procedimiento militar de tiempo de guerra el tiempo que se otorga al defensor para preparar el caso de su cliente está sujeto a la discreción de la autoridad militar que convoca al Consejo de Guerra.

En fin, la falta de garantías procesales, y los abusos más arriba señalados, producto de la aplicación de la jurisdicción militar de tiempo de guerra, infringe lo dispuesto, particularmente, en la letra d) del artículo $3^{\circ}$ común de los Convenios de Ginebra de 1949: “(...) quedan prohibidos, en cualquier tiempo y lugar: Las condenas dictadas y las ejecuciones efectuadas sin previo juicio, emitido por un tribunal regularmente constituido, provisto de garantías judiciales reconocidas como indispensables por los Pueblos civilizados".

Además, se debe considerar que el Gobierno Militar introdujo reformas y modificaciones a la legislación militar ${ }^{66}$, aumentando su competencia y las penas ${ }^{67}$, estable-

\footnotetext{
${ }^{64}$ Como se señala en el fallo Desafuero Pinochet (2000), considerando $3^{\circ}$, p. 534: “(...) el país se encontraba jurídicamente en 'estado o tiempo de guerra".

65 "Crímenes políticos como el denominado Caso de los pasaportes, en el que se investigó el asesinato del ex canciller don Orlando Letelier, o en el degollamiento de dirigentes políticos, o en caso de inhumaciones ilegales, entre otros graves crímenes, han sido amnistiados o no ha sido posible establecer las responsabilidades penales en los procesos judiciales tramitados en los tribunales militares" (LÓPEZ, 1995, p. 49).

66 V.g. Vid. Decreto Ley n 81, de 1973; Decreto Ley n ${ }^{\circ}$ 559, de 1974; Decreto Ley $n^{\circ}$ 604, de 1974; Decreto Ley ${ }^{\circ} 1.009$, de 1975; Decreto Ley n 3.655, de 1981.

67 "Así por ejemplo, el Decreto Ley no 425 (secreto) dictado entre el 15 y 30 de abril de 1974, establecía una serie de sanciones por delitos relativos a movilización nacional. Recién el 22 de julio de 1977 se publicó parte de este Decreto en el Diario Oficial. De esta forma, se aplicó a ciudadanos chilenos una ley cuyos tipos penales eran desconocidos y cuyas penas eran altísimas, violando con ello principios básicos de todo debido proceso. Añadido a ello, eran tribunales militares los que conocían de las causas que se ventilaran" (LÓPEZ, 1995, p. 32).
} 
ciendo privilegios para los militares sometidos a procesos judiciales ${ }^{68}$, utilizando la jurisdicción militar para la represión política ${ }^{69}$, todo lo cual redunda en un abuso a los derechos fundamentales de la persona humana, vulnerando principios básicos del Derecho Internacional Humanitario ${ }^{70}$ : respeto al debido proceso, presunción de inocencia, proporcionalidad de la pena, derecho a la justicia, independencia e imparcialidad del tribunal, publicidad, igualdad entre las partes, derecho de audiencia o a ser informado del proceso, derecho a aportar pruebas o cuestionarlas, derecho a no declarar contra sí mismo, derecho a recurrir a un tribunal superior, etc.

Por otra parte, de todas maneras serían aplicables los Convenios de Ginebra, sobre todo en consideración al derecho internacional consuetudinario que envuelven, por lo tanto, al menos deberían aplicarse los principios fundamentales del Derecho Humanitario. Los principios de los derechos humanos y del Derecho Internacional Humanitario reconocidos universalmente forman parte de valores comunes compartidos por todos. La Corte Internacional de Justicia ha afirmado acertadamente que las normas de Derecho Internacional Humanitario constituyen principios intransgredibles de derecho internacional consuetudinario ${ }^{71}$.

Es evidente que un gobierno no tiene enemigos más mortales que los individuos que quieren derrocar por la fuerza el régimen establecido. Así los considera, sin más, como criminales y querrá tener las manos libres para aplastar el levantamiento, sin que miradas indiscretas vengan a juzgar la legitimidad de los medios empleados. Objetivamente, todo golpe de Estado trae consigo alguna intención de tipo político, lo cual no es ajeno a lo sucedido en nuestro país en 1973. Se puede deducir el miedo existente ante la posibilidad de ver al país sumergido en el comunismo, de esta manera y con la intención de salvar y proteger la tradición e institucionalidad chilenas, un objetivo esencial fue el

68 "En virtud del Decreto Ley no 3.425, de 14 de junio de 1980, se amplió las personas que quedan sujetas a la jurisdicción militar, por el hecho de ser considerados militares: a) Los alumnos que efectúen los dos últimos años de estudios en las Escuelas Matrices para Oficiales de las Fuerzas Armadas; b) Los aspirantes a Oficiales que integran los cursos de la Escuela de Carabineros; c) Los cadetes, grumetes, aprendices y alumnos regulares de las Escuelas Institucionales que se encuentran en el caso del artículo 5 no 3 del Código de Justicia Militar (comisión de un delito común en estado de guerra, estando en campaña, en acto de servicio militar o con ocasión de él, etc.). Esta modificación trae consigo que son cada vez más las personas que quedan sujetas al fuero militar y por otro lado, gozan de dicho fuero en desmedro de la justicia ordinaria”. Ídem, pp. 113 y 114.

69 "El aumento de la competencia militar no tuvo fundamento real de Derecho, sino arbitrario hacia las personas y con un sentido político, propio del carácter autoritario del régimen, resultando los excesos cometidos en la tramitación y fallo de procesos de esa jurisdicción. La consecuencia lógica de este estado de cosas fue que los miembros de las Fuerzas Armadas actuaran como si estuvieran en una guerra, estando obligados legalmente a proceder como tal, y por lo mismo se les hizo aplicable la normativa internacional sobre derecho humanitario contenida en los Convenios de Ginebra de 1949”. Ídem, p. 130.

70 Para más detalle acerca de las reformas y modificaciones que introdujo el gobierno militar a la legislación militar, Vid. Ídem, pp. 31-43.

71 "La Corte Internacional de Justicia, en su sentencia de 27 de junio de 1986 se pronunció a favor de la existencia de principios generales básicos de Derecho Humanitario respecto a los que, a su juicio, los Convenios de Ginebra constituyen en ciertos aspectos el desarrollo y en otros la expresión, que corresponden a consideraciones elementales de humanidad". (SALINAS, 1998, p. 82). 
de aniquilar al enemigo. Es de público conocimiento que, detrás del comportamiento del Gobierno Militar y de los grupos armados subversivos, se perfilaba un conflicto de naturaleza política. Sin embargo, no hay razón alguna -ni aun la baja intensidad de los enfrentamientos- para dejar afuera todo principio humanitario, pues de ser así habría que resignarse al abandono completo de la exigencia mínima de humanidad en los conflictos bélicos, que constantemente ha inspirado el Derecho Internacional Humanitario.

Los principios básicos que deben guiar el comportamiento de las partes en un conflicto armado, con las personas que no participan en él, son el trato humanitario y la no discriminación. En todo conflicto bélico, aunque sea de baja intensidad o calificado de tensión o disturbio interior, deben existir consideraciones elementales de humanidad. Por lo tanto, los principios que emanan de los Convenios de Ginebra -aunque se postulase su no aplicación- son vinculantes por ser parte del derecho internacional consuetudinario, que pertenece a la categoría del ius cogens ${ }^{72}$. En las situaciones de disturbios internos, las normas del Derecho Internacional Humanitario pueden invocarse por analogía, y siempre los Estados deben respetar determinados principios humanitarios universalmente reconocidos, así como los instrumentos de derechos humanos de los que son parte, especialmente los derechos que no admiten ninguna derogación. Existe un tronco común de derechos que no admiten derogación y que se consideran como normas universales, de índole consuetudinaria: el derecho a la vida, la prohibición de la tortura y de las sanciones y los tratos crueles, inhumanos o degradantes; la prohibición de la esclavitud y de la servidumbre; el principio de legalidad y de no retroactividad de las penas. Por otra parte, determinadas garantías judiciales deben respetarse en todo momento para evitar las violaciones contra los derechos que no admiten derogación.

Como se pudo observar, en diversos fallos de la Corte Suprema se negaba la existencia de un conflicto armado interno en la época en cuestión, pues no se daría la característica de estar luchando dos bandos armados pertenecientes a las Fuerzas Armadas del gobierno, unos, y a las fuerzas armadas disidentes, otros. Se plantea de esta forma el problema de por qué no aplicar el Derecho Humanitario a los combatientes irregulares, es decir, a aquellos que luchan sin ser parte de las Fuerzas Armadas estructuradas. Además de las guerras regulares, ha habido siempre conflictos armados semejantes, pero que el derecho tradicional no consideraba como tales. Recibían los apelativos de rebeliones, luchas intestinas, insurrecciones, revoluciones y, más tarde, guerras civiles. En todo tiempo, tales guerras han provocado proporcionalmente más sufrimientos que los conflictos bélicos internacionales con razón del odio y del encarnizamiento correspondientes. Por ello, existen mayores razones para la aplicación de principios humanitarios en estos casos, pues las personas requieren de las mismas garantías para la protección de sus derechos fundamentales y dignidad humana, que en caso de guerra regular.

\footnotetext{
72 Como lo sostiene SALINAS (1998) p. 82, "Del análisis del contenido del artículo 3 común se desprende que en este se establecen normas humanitarias de naturaleza tan fundamental que sin temor a equivocarse puede decirse son verdaderas normas de ius cogens, cuya derogación no es posible en ninguna circunstancia y cuya aplicación va mas allá de cualquier vínculo convencional existente".
} 
De esta forma, aunque en Chile -como la mayoría de la jurisprudencia lo sostuvo- no hubiera existido un conflicto bélico efectivo, de todos modos debía aplicarse como un fundamental punto de partida de protección mínima el artículo $3^{\circ}$ común a todos los Convenios de Ginebra, donde se plasma el principio de humanidad. Las exigencias militares y el mantenimiento del orden público son siempre compatibles con el respeto de la persona humana, por ende, sea cual sea la situación fáctica debe existir un trato humanitario mínimo, en el cual se protejan esencialmente: la vida, la integridad física y mental, la no discriminación, la libertad y el debido proceso.

Además, como lo señalara el profesor Hugo Llanos, "lo principal es que las disposiciones de los Convenios de Ginebra deben aplicarse a todos aquellos que, de hecho, se encuentren en las situaciones previstas en sus Convenios, sin que sea necesario reparar en el calificativo dado por la autoridad a los hechos que han provocado la conmoción interna.

El ámbito de aplicación del artículo $3^{\circ}$ es que la resistencia armada al Gobierno tiene que haber promovido más que una acción normal de la policía para hacer cumplir las leyes penales y resultar en el empleo por el Gobierno, en alguna medida, de las Fuerzas Armadas. Esto, aun cuando la organización de los rebeldes y el control del territorio sean mínimas.

No ha sido fácil, en general, aplicar en la práctica este artículo $3^{\circ}$, debido a la oposición de los Estados a admitir la existencia de un conflicto armado dentro de su territorio. Cuando los Estados admiten su existencia, en general tienden a minimizarlos a fin de aplicar a los insurrectos su propia legislación interna"73.

En resumen, independiente de la calificación que se haga de los hechos ocurridos a partir del 11 de septiembre de 1973, debería aplicarse el Derecho Humanitario como normativa que garantiza la protección de la persona humana bajo estas situaciones, puesto que incluso en ciertos aspectos la protección ofrecida a los derechos humanos, por los instrumentos de Derecho Humanitario, es incluso superior a la que los propios instrumentos de derechos humanos garantizan, aparte de tener en consideración que bajo estado de excepción constitucional muchas garantías pueden verse mermadas, y más aún bajo la aplicación de la jurisdicción militar en tiempo de guerra. Por ejemplo, es relevante considerar que el artículo $3^{\circ}$ común a los cuatro Convenios de Ginebra hace referencia a las garantías de un debido proceso, en consecuencia, ellas deben ser respetadas incluso en el caso de un conflicto armado interno. Ello hace que resulte un contrasentido el que, bajo ciertos estados de excepción, se suspendan muchas de las garantías de un debido proceso, en circunstancias menos graves que un conflicto armado interno.

${ }^{73}$ LLANOS (1976) p. 44. 


\section{BIBLIOGRAFÍA CITADA}

Astrosa Herrera, Renato (1985): Código de Justicia Militar comentado: antecedentes, concordancias, jurisprudencia, referencia, leyes y reglamentos que lo complementan (Santiago, Editorial Jurídica de Chile, $3^{a}$ edición) 999 pp.

Calderón VARGas, Mario (1996): "La situación de los Derechos Humanos en Chile entre 1970 y 1989", Revista Chilena de Derecho vol. XXIII (nº 2 y 3, tomo I): pp. 223-253.

Comisión Chilena de Derechos Humanos (1994): Las deudas de la transición: balance de derechos humanos (Santiago, Ediciones Nacionales) 214 pp.

Comisión Interamericana de Derechos Humanos (1985): Informe sobre la situación de los Derechos Humanos en Chile (Washington, D.C., Secretaría General, Organización de los Estados Americanos) 371 pp.

Comité Internacional de la Cruz Roja (1975): Manual de la Cruz Roja Internacional: convenios, estatutos y reglamentos, resoluciones de la Conferencia Internacional de la Cruz Roja y del Consejo de Gobernadores de la Liga de Sociedades de la Cruz Roja (Ginebra, Comité Internacional de la Cruz Roja, 11ª edición) 645 pp.

EjérCito De Chile (1990): Presentación del Ejército de Chile a la Comisión Nacional de Verdad y Reconciliación (Santiago, Ejército de Chile) vol. I.

GonZÁleZ, Felipe (1993): "Derechos Humanos y Derecho Humanitario: Un análisis comparativo”, en: AA.VV., Dogmática Constitucional y Derechos Humanos (Santiago, Cuadernos de análisis jurídico 27, Escuela de Derecho, Universidad Diego Portales) pp. 21-48.

López DaWson, Carlos (1995): Justicia Militar. Una nueva mirada (Santiago, Comisión Chilena de Derechos Humanos) 142 pp.

Llanos Mansilla, Hugo (1976): "El derecho humanitario y su aplicación en caso de conflictos armados de carácter interno", Revista Chilena de Derecho vol. III: pp. 37-48.

Politzer, Patricia (1985): Miedo en Chile (Santiago, CESOC) 376 pp.

SAlinas BuRgos, Hernán (1998): "El Derecho Internacional Humanitario y los conflictos internos. Nuevos Desarrollos", en: Infante, María Teresa y CAVE, Rose (compiladoras), Nuevos estudios de Derecho Internacional Humanitario (Santiago, Instituto de Estudios Internacionales Universidad de Chile, Colección Estudios Internacionales) pp. 78-87.

Verdugo Marinkovic, Mario (1975): Código de Justicia Militar: ley de seguridad del estado, ley de control de armas. Textos anotados, concordancias, antecedentes históricos, jurisprudencia, fallos de Consejos de Guerra (Santiago, Ediciones Encina Ltda.) 655 pp.

Viera Gallo, José Antonio y Rodríguez Allendes, Teresa (1988): La derecha chilena $y$ los derechos humanos (Santiago, Academia de Humanismo Cristiano) 104 pp. 


\section{NORMAS CITADAS}

Código de Justicia Militar, 7a Edición Oficial 6 noviembre 1973, aprobada por Decreto no 1.373 del Ministerio de Justicia, 10 diciembre 1973.

Código de Justicia Militar, 9a Edición Oficial 31 mayo 1976, aprobada por Decreto $n^{\circ}$ 1.869 del Ministerio de Justicia, 12 noviembre 1976.

Código de Justicia Militar, 12a Edición Oficial 1 octubre 1984, aprobado por Decreto $\mathrm{n}^{\mathrm{o}} 1.132$ del Ministerio de Justicia, 21 diciembre 1984.

Código de Justicia Militar, 13a Edición Oficial 23 agosto 1985, aprobada por Decreto no 639 del Ministerio de Justicia, 30 julio 1986.

Decreto Ley ${ }^{\circ} 1$ del Ministerio de Defensa Nacional, Acta de constitución de la Junta de Gobierno. Diario Oficial, 18 septiembre 1973.

Decreto Ley $n^{\circ} 3$ del Ministerio de Defensa Nacional, Declara Estado de Sitio. Diario Oficial, 18 septiembre 1973.

Decreto Ley $\mathrm{n}^{\circ} 4$ del Ministerio de Defensa Nacional, Declara en estado de emergencia las provincias y departamentos que indica. Diario Oficial, 18 septiembre 1973.

Decreto Ley $n^{\circ} 5$ del Ministerio de Defensa Nacional, Declara que el estado de sitio decretado por conmoción interna debe entenderse "estado o tiempo de guerra". Diario Oficial, 22 septiembre 1973.

Decreto Ley no 13 del Ministerio de Defensa Nacional, Aclara sentido y alcance del artículo 73 del Código de Justicia Militar. Diario Oficial, 20 septiembre 1973.

Decreto Ley $n^{\circ} 81$ del Ministerio de Defensa Nacional, Fija, por razones de seguridad del Estado, sanciones para las personas que desobedezcan el llamamiento público que indica del Gobierno. Diario Oficial, 6 noviembre de 1973.

Decreto Ley $\mathrm{n}^{\circ} 559$ del Ministerio de Justicia, Modifica leyes $\mathrm{n}^{\text {os }} 12.927$, sobre seguridad del estado; 17.798, sobre control de armas, y D.F.L. $n^{\circ} 221$, de 1931, sobre navegación aérea. Diario Oficial, 12 julio 1974.

Decreto Ley $n^{\circ} 604$ del Ministerio del Interior, Prohíbe el ingreso de personas al territorio nacional en los casos que indica. Diario Oficial, 10 agosto 1974.

Decreto Ley $\mathrm{n}^{\circ} 640$ del Ministerio de Justicia, Sistematiza disposiciones relativas a regímenes de emergencia. Diario Oficial, 10 septiembre 1974.

Decreto Ley $\mathrm{n}^{\circ} 1.009$ del Ministerio de Justicia, Sistematiza normas sobre protección jurídica de los derechos procesales de los detenidos por delitos contra la seguridad nacional por los organismos que indica y modifica disposiciones legales que señala. Diario Oficial, 8 mayo 1975.

Decreto Ley no 2.191 del Ministerio del Interior, Concede amnistía a las personas que indica por los delitos que señala. Diario Oficial, 19 abril 1978.

Decreto Ley $\mathrm{n}^{\circ} 3.655$ del Ministerio del Interior, Sustituye artículo único del Decreto Ley $\mathrm{n}^{\circ} 3.627$ de 1981 que establece competencia de Tribunales Militares de tiempo de guerra en situaciones que indica. Diario Oficial, 17 marzo 1981. 


\section{JURISPRUDENCIA CITADA}

J.F.S.R. (1973): Corte Suprema 13 noviembre 1973, Verdugo (1975) pp. 100 y 101. Aycinema y Ramirez (1974): Consejo de Guerra Fuerza Aérea Chilena 19 abril 1974 (incompetencia por declinatoria de jurisdicción), Verdugo (1975) pp. 105-109.

Insunza Bascuñán (1990): Corte Suprema 24 agosto 1990 (recurso de inaplicabilidad), Revista de Derecho y Jurisprudencia, t. 87 (1990), II, secc. 4a, pp. 64-86.

Contra Romo Mena (1994 a): Corte de Apelaciones de Santiago 26 septiembre 1994, Diario El Mercurio, 2 octubre 1994, pp. D4 y D5.

Contra Romo Mena (1994 b): Corte de Apelaciones de Santiago 30 septiembre 1994 (recurso de apelación), Gaceta Jurídica, no 171 (septiembre 1994), pp. 127-136.

Contra Romo Mena (1995): Corte Suprema 26 octubre 1995 (recurso de queja), Gaceta Jurídica, no 185 (noviembre 1995), pp. 120-125.

Contra Romo Mena (1996): Corte Suprema 30 enero 1996 (recurso de queja), Revista Chilena de Derecho vol. 23 (nos 2 y 3, 1996), pp. 456-459.

Contra Romo Mena y otros (1996): Corte Suprema 3 diciembre 1996 (recurso de casación en el fondo), Revista de Derecho y Jurisprudencia, t. 93 (1996), II, secc. 4a, pp. 229-238.

Fiscalía de Aviación de Santiago con Dirección de Inteligencia de la Fuerza Aérea (1997): Juzgado de Aviación 18 julio 1997, LexisNexis (Base de datos electrónica de jurisprudencia), número identificador 25690.

Poblete Córdova (1997): Segundo Juzgado Militar de Santiago 22 abril 1997, Gaceta Jurídica no 219 (1998), pp. 114-115.

Contra Laureani Maturana y otro (1998): Corte Suprema 8 septiembre 1998 (recurso de casación en el fondo), Gaceta Jurídica, no 219 (1998), pp. 136-139.

Contra Romo Mena y otros (1998): Corte Suprema, 19 agosto 1998 (recurso de casación en el fondo), Gaceta Jurídica, no 218 (1998), pp. 125-134.

Pereira Salsberg y otros (1998): Corte Suprema 11 marzo 1998 (recurso de casación en el fondo), Revista de Derecho y Jurisprudencia, t. 95 (1998), II, secc. 4a , pp. 9-18.

Poblete Córdova (1998 a): Corte Marcial 19 enero 1998 (recurso de apelación), Gaceta Jurídica, no 219 (1998), pp. 115-119.

Poblete Córdova (1998 b): Corte Suprema 9 septiembre 1998 (recurso de casación en el fondo), Gaceta Jurídica no 219 (1998), pp. 119-126.

Corporación Nacional de Reparación y Reconciliación (1999): $2^{\circ}$ Tribunal Militar de Santiago 11 mayo 1999, LexisNexis (Base de datos electrónica de jurisprudencia), número identificador 26195.

Ponce Vicencio (1999): Juzgado Militar 2 diciembre 1999, LexisNexis (Base de datos electrónica de jurisprudencia), número identificador 33523.

Desafuero Pinochet Ugarte (2000): Corte Suprema 8 agosto 2000, Revista de Estudios Públicos $\mathrm{n}^{\circ} 79$ (invierno 2000), pp. 509-561.

Fiscalía de Aviación de Santiago con Dirección de Inteligencia de la Fuerza Aérea (2001): Corte Marcial 27 marzo 2001 (recurso de apelación), LexisNexis (Base de datos electrónica de jurisprudencia), número identificador 25690. 
Contreras Cabrera (2002): Corte Suprema 29 noviembre 2002 (recurso de casación en el fondo), LexisNexis (Base de datos electrónica de jurisprudencia), número identificador 29413.

Fiscalia de Aviación de Santiago con Dirección de Inteligencia de la Fuerza Aérea (2002): Corte Suprema 26 agosto 2002 (recurso de casación en el fondo), LexisNexis (Base de datos electrónica de jurisprudencia), número identificador 25690.

Corporación Nacional de Reparación y Reconciliación (2003 a): Corte Suprema 31 enero 2003 (recurso de casación en el fondo), LexisNexis (Base de datos electrónica de jurisprudencia), número identificador 26195.

Corporación Nacional de Reparación y Reconciliación (2003 b): Corte Suprema 31 enero 2003 (recurso de casación en el fondo, rol 4054-2001), LexisNexis (Base de datos electrónica de jurisprudencia), número identificador 26665.

Contra Rivera González y otro (2004): Corte de Apelaciones de Temuco 29 diciembre 2004, LexisNexis (Base de datos electrónica de jurisprudencia), número identificador 32543.

Contra Rivera González y otro (2005): Corte Suprema 4 agosto 2005 (recurso de casación en el fondo), LexisNexis (Base de datos electrónica de jurisprudencia), número identificador 32543 . 
